\title{
Correlation between Clinical Symptoms of Coeliac Disease, Serum IgA Anti TTG and Biopsy in Pediatric Population of Northern India
}

\author{
Sumit Jeena 1 , Jaswinder Kaur ${ }^{2}$, Nishant Wadhwa ${ }^{3}$ \\ ${ }^{1}$ Assistant Professor, Department of Paediatrics, Rajshree Medical Research Institute \& Hospital, Bareilly, Uttar Pradesh, India, ${ }^{2} \mathrm{Clinical}$ Associate, Department of Pediatric \\ Gastroenterology, Institute of Child Health, Sir Gangaram Hospital, New Delhi, India, ${ }^{3}$ Consultant, Department of Pediatric Gastroenterology, Institute of Child Health, Sir \\ Gangaram Hospital, New Delhi, India.
}

\section{Abstract}

Background: Celiac disease is basically an immune-mediated enteropathic condition produced by permanent sensitivity to gluten in genetically susceptible subjects. There is paucity of data in north India regarding clinical symptoms of coeliac disease, Serum IgA Anti TTG and Biopsy in pediatric population. The present study was conducted with the aim to determine the correlation between clinical symptoms of coeliac disease, Serum IgA Anti TTG and Biopsy in pediatric population of northern India. Materials and Methods: The present study was conducted in prospective including 73 pediatric patients at Department of Pediatric Gastroenterology, Institute of Child Health, Sir Gangaram Hospital, New Delhi, India. Esophagogastroduodenoendoscopy and serum anti Ig A tissue transglutaminase were performed. The characteristic scalloping of the folds were looked for in endoscopy followed by four duodenal biopsies performed from second part of duodenum and histological grading was performed as per modified marsh system. Patients with Serum IgA anti tTG>20 U/ml were confirmed to be at risk. Complete histological work up was done including hemoglobin, RBC indices and peripheral blood smear examination. The association of clinical manifestations with disease grade was also established with correlation coefficient. All the data thus obtained was arranged in a tabulated form and analyzed using SPSS software. Probability value of less than 0.05 was regarded as significant. Results: There were 4 males and 16 females with marsh grade 1 and 2 and mean age of $7.3 \pm 1.9$ years. There were 5 males and 8 females with marsh grade $3 \mathrm{a}$ and mean age of $6.8 \pm 2.3$ years. The mean weight of $18.11 \pm 3.89$, height of $103.17 \pm 8.73$ and BMI of $16.26 \pm 3.78$ was observed amongst subjects with Marsh grade 1 and 2. The mean weight of $15.12 \pm 3.17$, height of $99.28 \pm 9.19$ and BMI of $15.02 \pm 3.20$ was observed amongst subjects with Marsh grade 3a. Diarrhoea was maximum amongst subjects with grade 3c and 4(70\%) and minimum amongst Grade 1 and 2 (40\%). There was a significant difference between the frequency of anemia amongst different grades as the $\mathrm{p}$ value was less than 0.05. Conclusion: The most common presenting signs and symptoms were diarrhea and abdominal pain. The study also concluded that the incidence of anemia increases with higher marsh grades.

Keywords: Anemia, Celiac, Prospective, Marsh.

Corresponding Author: Dr. Sumit Jeena, Assistant Professor, Department of Paediatrics, RMRI, Bareilly, Uttar Pradesh, India.

Received: December 2019

Accepted: December 2019

\section{Introduction}

Celiac disease is basically an immune-mediated enteropathic condition produced by permanent sensitivity to gluten in genetically susceptible subjects. ${ }^{1}$ Initially it was regarded as malabsorption syndrome of younger ages but is now identified as a common disease that can be seen at any age group. The overall incidence of celiac disease in North India is approximately $1.04 \% .^{2}$ Clinical signs and symptoms vary vividly, classical celiac disease presents with diarrhea, steatorrhoea, loss of weight, while non-classical celiac disease presents with anemia, osteoporosis, osteopenia, steatosis, increased liver enzymes and aphthous stomatitis. ${ }^{3}$ Recent indications have debated on the practice of performing duodenal biopsies amongst all subjects testing positive for anti-tissue trans glutaminase antibodies and a hypothesis was advised that biopsy could be avoided amongst patients with increased titers of serum antibody levels.4 $^{4-7}$ As per European Society of Pediatric Gastroenterology, Hepatology and Nutrition guidelines published in 2019 have recommended that The no-biopsy approach for $\mathrm{CD}$ diagnosis is safe in children with high TGA-IgA values ( $\geq 10$ times the upper limit of normal) with appropriate tests and positive endomysial antibodies (EMA$\operatorname{IgA}$ ) in a second serum sample. Children with positive TGA-IgA but lower titers (<10 times upper limit of normal) should undergo biopsies to decrease the risk of false positive diagnosis. HLA testing and presence of symptoms are not obligatory criteria for a serology based diagnosis without biopsies. There is paucity of data in north India regarding clinical symptoms of coeliac disease, Serum IgA Anti TTG and Biopsy in pediatric population. The present study was conducted with the aim to determine the correlation between clinical symptoms of coeliac disease, Serum IgA Anti TTG and Biopsy in pediatric population of northern India. 


\section{Subjects and Methods}

The present study was conducted in prospective including 73 pediatric patients at Department of Pediatric Gastroenterology, Institute of Child Health, Sir Gangaram Hospital, New Delhi, India. The study was approved by the institutional ethical board and all the subjects were informed about the study and a written consent was obtained form them in their vernacular language. A total of 73 subjects with suspected malabsorption syndrome were examined in this study. Pediatric patients (age-1-15 years) with following symptom groups: gastrointestinal symptoms ( diarrhea, Constipation, vomiting, pain abdomen and abdominal distention) and extra intestinal manifestations ( anemia, short stature and type I diabetes mellitus) were enrolled. Three siblings of confirmed patients were also enrolled. Complete history and clinical examination were done.

Esophagogastroduodenoendoscopy and serum anti Ig A tissue transglutaminase were performed. The characteristic scalloping of the folds were looked for in endoscopy followed by four duodenal biopsies performed from second part of duodenum and histological grading was performed as per modified marsh system (Table 1A). Serum IgA Anti tTG levels were performed by enzyme linked immunosorbent assay (ELISA).Patients with Serum IgA anti tTG>20 U/ml were confirmed to be at risk. Complete histological work up was done including hemoglobin, RBC indices and peripheral blood smear examination. The association of clinical manifestations with disease grade was also established with correlation coefficient. All the data thus obtained was arranged in a tabulated form and analyzed using SPSS software. Probability value of less than 0.05 was regarded as significant.

\section{Results}

The The study enrolled a total of 73 patients. Table 1 shows the gender and age distribution according to Marsh grade. There were 4 males and 16 females with marsh grade 1 and 2 and mean age of $7.3 \pm 1.9$ years. There were 5 males and 8 females with marsh grade $3 \mathrm{a}$ and mean age of $6.8 \pm 2.3$ years. There were 12 males and 8 females with marsh grade $3 \mathrm{~b}$ and mean age of $7.1 \pm 1.7$ years. There were 9 males and 11 females with marsh grade $3 c$ and 4 and mean age of $6.9 \pm 2.2$ years. There was no significant difference between the gender distribution and marsh scale.

\section{Table 1a: Marsh Grading}

\begin{tabular}{|l|l|}
\hline Marsh grade & Histological features \\
\hline $\mathbf{0}$ & Normal mucosa \\
\hline $\mathbf{1}$ & Increased number of intraepithelial lymphocytes, usually exceeding 30 per 100 enterocytes \\
\hline $\mathbf{2}$ & Perforation of cysts of liberkuhn \\
\hline $\mathbf{3}$ & Variable villous atrophy \\
\hline 3a & Partial villous atrophy \\
\hline 3b & Subtotal villous atrophy \\
\hline 3c & Total villous atrophy \\
\hline $\mathbf{4}$ & Hypoplasia of small bowel architecture \\
\hline
\end{tabular}

Table 1: Gender and age distribution according to Marsh grade

\begin{tabular}{|c|c|c|c|c|c|}
\hline \multirow[t]{2}{*}{ Parameters } & \multicolumn{4}{|c|}{ Marsh Grade } & \multirow[t]{2}{*}{ p value } \\
\hline & $1+2(\mathrm{~N}=20)$ & $3 a(N=13)$ & $3 b(N=20)$ & $3 c+4(N=20)$ & \\
\hline Male $(\mathbf{N}, \%)$ & $4(20)$ & $5(38.46)$ & $12(60)$ & $9(45)$ & 0.23 \\
\hline Female (N, \%) & $16(80)$ & $8(61.54)$ & $8(40)$ & $11(55)$ & \\
\hline Age in years (Mean \pm SD) & $7.3 \pm 1.9$ & $6.8 \pm 2.3$ & $7.1 \pm 1.7$ & $6.9 \pm 2.2$ & 0.67 \\
\hline
\end{tabular}

Table 2: Weight, height and BMI according to Marsh grade

\begin{tabular}{|l|c|c|c|c|c|}
\hline \multirow{2}{*}{ Parameters } & \multicolumn{3}{|c|}{ Marsh Grade } & \multicolumn{2}{c|}{ p value } \\
\cline { 2 - 6 } & $\mathbf{1 + 2}(\mathbf{N}=\mathbf{2 0})$ & $\mathbf{3 a}(\mathbf{N}=\mathbf{1 3})$ & $\mathbf{3 b}(\mathbf{N}=\mathbf{2 0})$ & $\mathbf{3 c + 4}(\mathbf{N}=\mathbf{2 0})$ & $14.08 \pm 2.9$ \\
\hline Weight $($ Mean \pm SD) & $18.11 \pm 3.89$ & $15.12 \pm 3.17$ & $14.67 \pm 3.40$ & $0.03^{*}$ \\
\hline Height (Mean \pm SD) & $103.17 \pm 8.73$ & $99.28 \pm 9.19$ & $97.09 \pm 10.12$ & $95.29 \pm 10.58$ & $0.04^{*}$ \\
\hline BMI (Mean \pm SD) & $16.26 \pm 3.78$ & $15.02 \pm 3.20$ & $14.71 \pm 2.97$ & $14.08 \pm 3.14$ & $0.02^{*}$ \\
\hline
\end{tabular}

$$
\text { *: statistically significant }
$$

\section{Table 3: Abdominal and other symptoms according to Marsh grade}

\begin{tabular}{|l|c|c|c|c|c|}
\hline \multirow{2}{*}{ Parameters } & \multicolumn{3}{|c|}{ Marsh Grade } & p value \\
\cline { 2 - 5 } & $\mathbf{1 + 2}(\mathbf{N}=\mathbf{2 0})$ & $\mathbf{3 a}(\mathbf{N}=\mathbf{1 3})$ & $\mathbf{3 b}(\mathbf{N}=\mathbf{2 0})$ & $\mathbf{3 c + 4}(\mathbf{N}=\mathbf{2 0})$ & $14(70)$ \\
\hline Diarrohea (N, \%) & $8(40)$ & $7(53.85)$ & $12(60)$ & $0.04 *$ \\
\hline Vomiting (N, \%) & $7(35)$ & $5(38.46)$ & $9(45)$ & $10(50)$ \\
\hline Pain Abdomen (N, \%) & $7(35)$ & $6(46.15)$ & $11(55)$ & $13(65)$ & 0.07 \\
\hline Abdominal Distension (N, \%) & $2(10)$ & $5(38.46)$ & $8(40)$ & $9(45)$ & 0.06 \\
\hline Constipation (N, \%) & $2(10)$ & $4(30.77)$ & $6(30)$ & $9(45)$ & $0.04 *$ \\
\hline Not gaining weight (N, \%) & $13(65)$ & $10(76.92)$ & $18(90)$ & $20(100)$ & $0.03 *$ \\
\hline
\end{tabular}




\section{Jeena et al; Carrelatian letween Clinical Symptams of Caeliac Disease, Serum IgA Anti JTG and Biapsy}

Table 4: Anorexia and anemia according to Marsh grade

\begin{tabular}{|l|c|c|c|c|c|}
\hline Parameters & \multicolumn{3}{|c|}{ Marsh Grade } & \multicolumn{2}{c|}{ p value } \\
\cline { 2 - 6 } & $\mathbf{1 + 2}(\mathbf{N}=\mathbf{2 0})$ & $\mathbf{3 a}(\mathbf{N}=\mathbf{1 3})$ & $\mathbf{3 b}(\mathbf{N}=\mathbf{2 0})$ & $\mathbf{3 c + 4}(\mathbf{N}=\mathbf{2 0})$ & \\
\hline Anorexia (N, \%) & $2(10)$ & $4(30.77)$ & $6(30)$ & $9(45)$ & 0.08 \\
\hline Anemia (N, \%) & $5(25)$ & $4(30.77)$ & $13(65)$ & $14(70)$ \\
\hline
\end{tabular}

*: statistically significant

Table 5: Mean serum IgA anti TTG levels according to Modified Marsh Grade
\begin{tabular}{|l|c|c|c|}
\hline Modified Marsh Grade & N & Mean & \\
\hline $\mathbf{1 + 2}$ & 20 & 28.55 & 7.13 \\
\hline $\mathbf{3 a}$ & 13 & 39.00 & 11.51 \\
\hline $\mathbf{3 b}$ & 20 & 53.80 & 15.50 \\
\hline $\mathbf{3 c}+\mathbf{4}$ & 20 & 84.00 & 8.49 \\
\hline ANOVA test & & 47.35 & \\
\hline $\mathbf{p}$ value & \multicolumn{3}{l|}{$<0.01^{*}$} \\
\hline
\end{tabular}

[Table 2] illustrates the weight, height and BMI according to Marsh grade. The mean weight of $18.11 \pm 3.89$, height of $103.17 \pm 8.73$ and BMI of $16.26 \pm 3.78$ was observed amongst subjects with Marsh grade 1 and 2. The mean weight of 15.12 \pm 3.17 , height of 99.28 \pm 9.19 and BMI of $15.02 \pm 3.20$ was observed amongst subjects with Marsh grade $3 \mathrm{a}$. The mean weight of $14.67 \pm 3.40$, height of $97.09 \pm 10.12$ and BMI of $14.71 \pm 2.97$ was observed amongst subjects with Marsh grade $3 \mathrm{~b}$. The mean weight of $14.08 \pm 2.9$, height of $95.29 \pm 10.58$ and BMI of 14.08 \pm 3.14 was observed amongst subjects with Marsh grade $3 \mathrm{c}$ and 4 . There was a statistically significant difference in weight, height and BMI amongst different Marsh grades.

Table 3 shows the Abdominal and other symptoms according to Marsh grade. Diarrhoea was maximum amongst subjects with grade $3 \mathrm{c}$ and $4(70 \%)$ and minimum amongst Grade 1 and $2(40 \%)$. There was a significant difference in the incidence of diarrhea amongst different grades. No significant difference was observed in vomiting and abdominal pain amongst all the grades. There were $45 \%$ subjects with grade $3 c$ and 4 and $40 \%$ with grade $3 b$ and $10 \%$ with grade 1 and 2 having abdominal distention, indicating significant difference between the grades.

Table 4 shows the incidence of Anorexia and anemia according to Marsh grade. Anorexia was observed amongst $10 \%$ patients with grade 1 and $2,30.77 \%$ patients with grade $3 \mathrm{a}, 30 \%$ patients with grade $3 \mathrm{~b}$ and $45 \%$ patients with grade $3 \mathrm{c}$ and 4 . There was no significant difference between the frequency of anorexia amongst different grades as the $\mathrm{p}$ value was more than 0.05 . Anemia was observed amongst $25 \%$ patients with grade 1 and $2,30.77 \%$ patients with grade $3 \mathrm{a}, 65 \%$ patients with grade $3 \mathrm{~b}$ and $70 \%$ patients with grade $3 \mathrm{c}$ and 4 . There was a significant difference between the frequency of anemia amongst different grades as the $\mathrm{p}$ value was less than 0.05. Table 5 shows Mean serum IgA anti TTG levels according to Modified Marsh Grade.

\section{Discussion}

Malabsorption is a disorder that is considered by defective absorption of fats, carbohydrates, proteins, and vitamins, electrolytes and minerals. Celiac disorder is regarded as one of the most frequent reasons of malabsorption. ${ }^{8}$ In 2013, Oslo told that Celiac diseases are a chronic small intestinal immunologically-mediated enteropathy that is initiated in genetically predisposed patients due to exposure to dietary gluten. ${ }^{[9]}$ Celiac disease, also known as gluten-sensitive enteropathy, non-tropical sprue and endemic sprue. It is basically a autoimmune condition that is triggered by the ingesting wheat gluten and associated proteins of barley and rye amongst genetically susceptible populace. ${ }^{10}$ Wellidentified prototypes amongst human leukocyte antigen class II region such as HLA-DQ8 and HLA-DQ2 produce this genetic susceptibility. ${ }^{[11]}$ The incidence of having Celiac disorder is more amongst first-degree relatives $(10 \%)$ and is $5 \%$ amongst second-degree relatives, also amongst people with autoimmune conditions, diabetes, Down's syndrome and several other related conditions. ${ }^{[12]}$ A certain diagnosis of Celiac condition is dependent on histological alterations, like intraepithelial lymphocytosis, hyperplasia, and varying frequency of villous atrophy, that are graded as per a classification system given by Marsh in 1992 and now extensively used as a modification of Marsh grading. ${ }^{13-16}$ Duodenal biopsy is the gold standard for detecting Celiac disease, even with the presence of very specific serologic tests Such as anti-gluten and anti-tissue transglutaminase antibodies. Association of clinical, serologic, and histological outcomes are crucial for the definitive diagnosis of this disease. ${ }^{17}$ As per the present study, there were 4 males and 16 females with marsh grade 1 and 2 and mean age of $7.3 \pm 1.9$ years. There were 5 males and 8 females with marsh grade $3 \mathrm{a}$ and mean age of $6.8 \pm 2.3$ years. There were 12 males and 8 females with marsh grade $3 \mathrm{~b}$ and mean age of $7.1 \pm 1.7$ years. There were 9 males and 11 females with marsh grade $3 c$ and 4 and mean age of $6.9 \pm 2.2$ years. There was no significant difference between the gender distribution and marsh scale. The mean weight of $18.11 \pm 3.89$, height of $103.17 \pm 8.73$ and BMI of $16.26 \pm 3.78$ was observed amongst subjects with Marsh grade 1 and 2 . The mean weight of $15.12 \pm 3.17$, height of $99.28 \pm 9.19$ and BMI of $15.02 \pm 3.20$ was observed amongst subjects with Marsh grade $3 \mathrm{a}$. The mean weight of $14.67 \pm 3.40$, height of 


\section{Jeena et al; Carrelatian letween Clinical Symptams of Caeliac Disease, Serum IgA Anti JTG and Biapsy}

$97.09 \pm 10.12$ and BMI of $14.71 \pm 2.97$ was observed amongst subjects with Marsh grade $3 \mathrm{~b}$. The mean weight of $14.08 \pm 2.9$, height of $95.29 \pm 10.58$ and BMI of $14.08 \pm 3.14$ was observed amongst subjects with Marsh grade $3 \mathrm{c}$ and 4 . There was a statistically significant difference in weight, height and BMI amongst different Marsh grades. Diarrhoea was maximum amongst subjects with grade $3 \mathrm{c}$ and $4(70 \%)$ and minimum amongst Grade 1 and 2 (40\%). There was a significant difference in the incidence of diarrhea amongst different grades. No significant difference was observed in vomiting and abdominal pain amongst all the grades. There were $45 \%$ subjects with grade $3 c$ and 4 and $40 \%$ with grade $3 \mathrm{~b}$ and $10 \%$ with grade 1 and 2 having abdominal distention, indicating significant difference between the grades. Anorexia was observed amongst $10 \%$ patients with grade 1 and 2, 30.77\% patients with grade 3a, 30\% patients with grade $3 \mathrm{~b}$ and $45 \%$ patients with grade $3 \mathrm{c}$ and 4 . There was no significant difference between the frequency of anorexia amongst different grades as the $\mathrm{p}$ value was more than 0.05 . Anemia was observed amongst $25 \%$ patients with grade 1 and $2,30.77 \%$ patients with grade $3 \mathrm{a}, 65 \%$ patients with grade $3 \mathrm{~b}$ and $70 \%$ patients with grade $3 \mathrm{c}$ and 4 . There was a significant difference between the frequency of anemia amongst different grades as the $\mathrm{p}$ value was less than 0.05 . Past studies have also demonstrated female predominance. ${ }^{[18-20]}$ Anti-tTG levels in grades $3 c+4$ were maximum in all grades. ${ }^{[19]}$ As per Rahmati A et al, who examined 159 subjects also demonstrated an elevated trend in mean tTG antibody levels from normal. ${ }^{[18]}$ As per the study by Vivas $\mathrm{S}$ et al, amongst 97 children and 227 adults also observed that the mean tTG antibody titer showed a progressive elevation with increasing Marsh grades amongst both pediatric and adults. The level of tTG antibody was also correlating significantly with different Marsh types in the complete population. ${ }^{[21]}$

\section{Conclusion}

The incidence of celiac disease was more amongst females than males. The most common presenting signs and symptoms were diarrhea and abdominal pain. The study also concluded that the incidence of anemia increases with higher marsh grades.

\section{References}

1. Kagnoff MF. Overview and pathogenesis of celiac disease. Gastroenterology. 2005;128:S10-8.

2. Makharia GK, Verma AK, Amarchand R et al. Prevalence of celiac disease in the northern part of India: a community based study. J
Gastroenterol Hepatol. 2011;26(5):894-900.

3. Ludvigsson JF, Leffler DA, Bai JC et al. The Oslo definitions for coeliac disease and related terms. Gut. 2013;62:6243-52.

4. Barker CC, Mitton C, Jevon G, et al. Can tissue transglutaminase antibody titers replace small bowel biopsy to diagnose celiac disease in selected pediatric populations? Pediatrics. 2005;115:1341-6.

5. Vivas S, Ruiz de Morales JG, Riestra S, et al. Duodenal biopsy maybe avoided when high transglutaminase antibody titers are present. World J Gastroenterol. 2009;15:4775-80.

6. Donaldson MR, Firth SD, Wimpee H, et al. Correlation of duodenal histology with tissue transglutaminase and endomysial antibody levels in pediatric celiac disease. Clin Gastroenterol Hepatol. 2007;5:567-73.

7. Tortora R, Imperatore N, Capone P, De Palma GD.The presence of anti-endomysial antibodies and the level ofanti-tissue transglutaminases can be used to diagnose adult coeliac disease without duodenal biopsy. Aliment Pharmacol Ther.2014;40:1223-29.

8. Kumar V, Abbas A, Fausto N, Aster J. Robbins and Cotran pathologic basis of disease. 8th ed. Chapter 17, The gastrointestinal tract; p.793-94.

9. Kang JY, Kang AH, Green A, Gwee KA, Ho KY. Systematic review: worldwide variation in the frequency of coeliac disease and changes over time. Aliment PharmacolTher2013; 38: 226-45.

10. Briani C, Samaroo D, Alaedini A. Celiac disease: From gluten to autoimmunity. Autoimmun Rev 2008; 7: 644-50.

11. Setty M, Hormaza L, Guandalini S. Celiac disease: Risk assessment, diagnosis, and monitoring. Mol DiagnTher 2008; 12:289-98.

12. Fasano A, Berti I, Gerarduzzi T, Not T, Colletti RB, Drago Set al. Prevalence of Celiac disease in at-risk and not-at-risk groups in the Unites States: a large multicenter study. Arch Intern Med 2003; 163: 286-92.

13. Green PH, Jabri B. Coeliac disease. Lancet 2003; 362: 383-91.

14. Ciclitira PJ, King AL, Fraser JS. AGA technical review on Celiac Sprue American Gastroenterological Association Gastroenterology. 2001;120: 1526-40.

15. Rostami K, Kerckhaert J, Tiemessen R, von Blomberg BM, Meijer JW, Mulder CJ. Sensitivity of antiendomysium and antigliadin antibodies in untreated Celiac disease: disappointing in clinical practice. Am J Gastroenterol1999; 94: 888-94.

16. Oberhuber G, Granditsch G. The histopathology of coeliac disease: time for a standardized report scheme for pathologists. Eur J Gastroenterol Hepatol 1999; 11: 1185-94.

17. Heredia PC, Castro PF. Adult Celiac disease. Rev Med Chil2007; 135:1186-94.

18. Rahmati A, Shakeri R, Sohrabi MR, Alipour A, Boghratian AH, Setareh $\mathrm{M}$ et al. Correlation of Tissue Transglutaminase Antibody with Duodenal Histologic Marsh Grading. Middle East J Dig Dis 2014; 6:131-6.

19. Kalhan S, Joseph P, Sharma S, Dubey S, Dudani S, Dixit M. Comparative study of histopathological Marsh grading with clinical and serological parameters in Celiac iceberg of north India. Indian J Pathol Microbiol 2011; 54:279-83.

20. Singh P, Kurray L, Agnihotri A, Das P, Verma AK, Sreenivas V, et al. Titers of Anti-tissue Transglutaminase Antibody Correlate Well With Severity of Villous Abnormalities in Celiac Disease. J Clin Gastroenterol 2015; 49:212-17.

21. Vivas S, Ruiz de Morales JG, Riestra S, Arias L, Fuentes D, Alvarez $\mathrm{N}$, et al. Duodenal biopsy may be avoided when high transglutaminase antibody titers are present. World J Gastroenterol $2009 ; 15: 4775-80$.

Copyright: (C) the author(s), 2020. It is an open-access article distributed under the terms of the Creative Commons Attribution License (CC BY 4.0), which permits authors to retain ownership of the copyright for their content, and allow anyone to download, reuse, reprint, modify, distribute and/or copy the content as long as the original authors and source are cited.

How to cite this article: Jeena S, Kaur J, Wadhwa N. Correlation between Clinical Symptoms of Coeliac Disease, Serum IgA Anti TTG and Biopsy in Pediatric Population of Northern India. Asian J. Clin. Pediatr. Neonatol.2020;8(1):65-68.

DOI: dx.doi.org/10.47009/ajcpn.2020.8.1.16

Source of Support: Nil, Conflict of Interest: None declared. 